\title{
Investigative advising: a job for Bayes
}

Jared C Allen

\begin{abstract}
Background: Bayesian approaches to police decision support offer an improvement ypo nore commonly used statistical approaches. Common approaches to case decision support often involve $a$ fro, ricies from cases similar to the case under consideration to come to an isolated likelihood that a given su. ct, either a) committed the crime or b) has a given characteristic or set of characteristics. The Bayesian a roach, 1, contrast, offers formally contextualized estimates and utilizes the formal logic desired by investigators.

Findings: Bayes' theorem incorporates the isolated likelihood as one elemer of a thee-part equation, the other parts being 1) what was known generally about the variables in the cas risurne case occurring (the scientific-theoretical priors) and 2) the relevant base rate information that a textualizes the evidence obtained (the event context). These elements are precisely the domain of $d t$ support specialists (investigative advisers), and the Bayesian paradigm is uniquely apt for combining them intd cony,xtualized estimates for decision support. Conclusions: By formally combining the relevant knowledge, contex and likelihood, Bayes' theorem can improve the logic, accuracy, and relevance of decision support ants.
\end{abstract}

Keywords: Investigative advising; Decision support; Bl, Payes In statistics; Police investigations

\section{Findings}

Police investigators occasionally seek the $s$ pport or cialists in various fields. Cases of murder ana ne, for instance, prompt the need to utilize all arailable sources to prevent future offending by the rerpetrators, and serial offenses (believed to have a single $\mathrm{p}$ etrator) can prompt the employment of consultants to lin. crimes and anticipate likely sites of future ding (or the offender's "home base"; Rossmo 2000, 2009. Wyodhams et al. 2007). The statistical trainirg d specializations of academic criminologists and candidates for such consultancy ( on and Rainbow 2011). In the United Kingrio (and scme other Western countries) law enforcement encies have such consultants on staff. The task of these professionals is referred to as Beharı anve tigative Advising (BIA).

The fiela \& BA is young and still establishing profesona and scientific standards (Dowden et al. 2007; Alison a. Kambow 2011). The research literature and empirical basis 1 BIA are rapidly expanding and improving (Dowden et al. 2007; Almond et al. 2011). Investigators have reported that BIA consultancy is useful both as a

Correspondence: jared.allen@psych.ryerson.ca

Department of Psychology, Ryerson University, Toronto, Canada second opinion and as a decision support tool (Rainbow 2011). This tool aims to be accurate, useful, specific, and falsifiable (Alison et al. 2003). This assures the consultancy is beneficial to police and allows for the product to be evaluated after the investigation.

The advising process can be summarized generally as using the knowns of an investigation to estimate unknowns useful to investigators; for example, moving from the known locations of a series of crimes to the possible residence or workplace of the offender (Rossmo 2000). BIA consultants can assist in locating, describing, and prioritizing suspects by contributing scientific knowledge and formal analysis of "national datasets and other relevant base rate data" (Rainbow et al. 2011 p. 37). That is, their contribution is the assimilation of research literature, evidence, and context to optimize decision making.

Due in part to its recent genesis as a scientific field of study, there are a multitude of quantitative approaches used by BIA professionals to arrive at estimates for decision support. The vast majority of these (e.g., correlation, Jaccard's indices, chi-square tests, logistic regression) may aptly be called "frequentist". That is, the majority of approaches involve either interpreting likelihoods from 


\section{(a) $P(\mathrm{H} \mid \mathrm{O})=P(\mathrm{O} \mid \mathrm{H}) * P(\mathrm{H}) / P(\mathrm{O})$ \\ (b) Posterior $=$ Likelihood $*$ Prior $/$ Normalizing constant

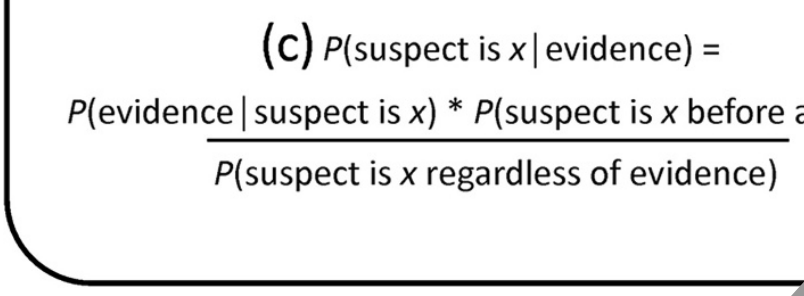

Figure 1 Bayes' Theorem expressed in a) probability statements, b) Bayesian terms, and c' in. 'igative language.

frequency data or utilizing null hypothesis significance testing to interpret estimates of unknowns.

Bayesian statistical inference is the algorithmic combination of previous and new data to obtain the probability of one or more causes producing the new data (Gill 2009; de Morgan 1838). This is different from inferring the simple probability of said data being observe a (randomly or otherwise), which is the cornerstone of more commonly used frequentist methods.

Bayes' theorem formally combines quantific tiol s of one's pre-analysis information (a prior), some ba rate criminological and demographic data normaı ng constant), and a likelihood of obtainin on evidence. As shown in Figure 1, the prior and Melihood a 2 multiplied together and divided by the tormalizing constant, yielding on ne conclusion or estimate (the posterior). This is more nerany expressed as: The probability of a hypothesis $(\mathrm{H})$ \& en an observation $(\mathrm{O})$ is equal to the probab my obtaining the observation given the hypothesis is true, multiplied by the prior probability of the hypot Mesis, divided by the unconditional probability obtaining the observation.

ey distinctions between Bayesian and frequentist (a) so called Fisherian) approaches to BIA estimation are the use of a null hypothesis and the use of prior information. Bayesian logic involves treating data as constant and modelling one's belief about relationships in the data based on the context of the data and the data, whereas frequentist logic involves treating the data as random, ignoring the context of the information so as to be

Table 1 Differences between Bayesia

requentist/Fisherian approaches to investigative inference

\begin{tabular}{|c|c|c|}
\hline & Bayesian & Frequentist/Fisherian \\
\hline \multirow{6}{*}{$\begin{array}{l}\text { Context } \\
\text { Null hypothesis }\end{array}$} & Incorporates past kn pyledge & Ignores past knowledge \\
\hline & a stren $c h$ of the evidence & $\begin{array}{l}\text { Result typically (but not necessarily) based on } \\
\text { assumption of no effect or assumption of a statement } \\
\text { counterfactual to one's question }\end{array}$ \\
\hline & $\begin{array}{l}\text { describing the relationships within the data are treated } \\
\text { in some distribution. (e.g., in Markov chain Monte Carlo }\end{array}$ & $\begin{array}{l}\text { The data are treated as random so that the likelihood } \\
\text { of obtaining it under the null can be assessed }\end{array}$ \\
\hline & ', moving from effect to estimation of cause & $\begin{array}{l}\text { Typically uses null logic: rejection of no effect } \\
\text { to infer effect }\end{array}$ \\
\hline & $\begin{array}{l}\text { Probability is a measure of evidence, belief, or willingness } \\
\text { to gamble based on all available information }\end{array}$ & Probability is relative frequency over time. \\
\hline & "The probability of $\mathrm{H}$, given the evidence, is $\mathrm{x} \%$ " & $\begin{array}{l}\text { "If its contrary were true, then the chances of } \mathrm{H} \text { (or a } \\
\text { more extreme statement of } \mathrm{H} \text { ) would be less than } \mathrm{x} \% \text { " }\end{array}$ \\
\hline $\begin{array}{l}\text { Primary } \\
\text { difficulty }\end{array}$ & $\begin{array}{l}\text { New information must compete with old, making the process } \\
\text { of discovery more conservative and necessarily cumulative }\end{array}$ & $\begin{array}{l}\text { The assumption of no difference is always false. } \\
\text { Given a large enough sample size, any difference } \\
\text { will be found statistically significant. }\end{array}$ \\
\hline $\begin{array}{l}\text { Pragmatic } \\
\text { difficulty for BIA }\end{array}$ & $\begin{array}{l}\text { Determining the measure of one's priors can be difficult, and Bayesian } \\
\text { methods can be perceived as unscientific, especially in legal circles }\end{array}$ & $\begin{array}{l}\text { Does not produce estimates of the form typically } \\
\text { desired (e.g., "a } 77 \% \text { chance"), and results logically } \\
\text { pertain to the data itself, not to the prediction } \\
\text { of new cases }\end{array}$ \\
\hline
\end{tabular}


"objective", and-typically-evaluating the existence of a relationship from the initial standpoint of the assumption that no relationship exists. Table 1 details key relevant differences between Bayesian and frequentist approaches to statistical inference. Note, however, that some exceptions to these differences may exist, especially when considering very simple applications of Bayes' theorem and very complex applications of frequentist statistics.

Bayes' theorem can be effective both as a tool and as an analogue to the logical problems faced by investigators. Tartoni et al. (2006) note that Bayesian analysis is well-suited for nearly all aspects of forensic investigation, and Schneps and Colmez (2013) illustrate the grievous errors that can occur when cases are built solely based on an isolated frequentist analysis of the evidence. For example, calculating a simple 1 in 6 chance of identifying an offender from a line-up versus a 1 in 12 chance may lead one to believe that having more individuals as foils in a police line-up increases the poss a pro ability that an accurate match was made. Wells $d$ Turtle (1986) noted that this is not the se. They also shed empirical light, using a Bayesian upa. $\mathrm{m}$.odel, on the practice of having all-suspect ine-ups, w ach they found increases the risk of false ide ificatior).

Blair and Rossmo (20? ר) ta the issue of assigning prior probability valurs fo, ecision support. They argue

Table 2 Procedural comparisons based on a (highly simplified) investigative advising -mple

Example case
Given: Two homicide cases in which knives and strangle wires were used (i.e., a knife an, rangle-wire were used in case 1 and a knife and
Task: Assess whether
a) the two cases are linked (i.e., they have a common offender), and
b) the offender was known or a stranger to the victims.

\section{Dimensional frequentist approach}

a) Case linkage
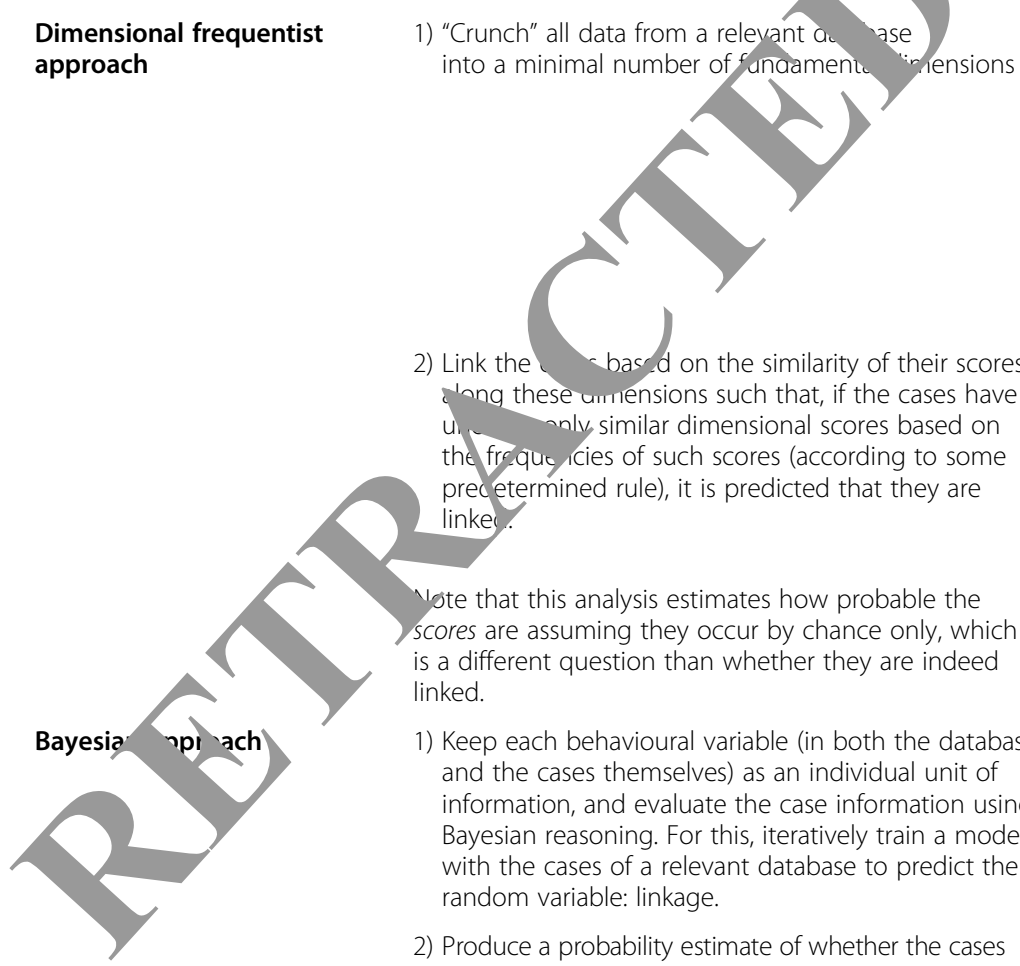

1) "Crunch" all data from a relevant a case
into a minimal number of fandament in 2) Link the bas.d on the similarity of their scores u. nly similar dimensional scores based on the frequy icies of such scores (according to some prec etermined rule), it is predicted that they are linkes.

'ote that this analysis estimates how probable the scores are assuming they occur by chance only, which is a different question than whether they are indeed linked.

1) Keep each behavioural variable (in both the database and the cases themselves) as an individual unit of information, and evaluate the case information using Bayesian reasoning. For this, iteratively train a model with the cases of a relevant database to predict the random variable: linkage.

2) Produce a probability estimate of whether the cases are linked given their behavioural variable values. That is, combine using Bayes' theorem the case information and the trained model developed from the database, into a posterior estimate. This approach treats the conditional likelihood (from "a 2" above) as only one element of the linkage estimate.

\section{b) Offender characteristic}

1) The dimensional scores of the cases (obtained for "a") point vaguely to certain offender characteristics that belong to or have similar dimensional scores as the cases themselves (e.g., given the offender used both a knife and a strangle wire, this may yield a higher score on a "sadism" dimension. Assume being a stranger offender is associated with sadism: If the offender is a stranger, then the evidence is more likely than the evidence would be if the offender were not a stranger).

2) Use more specific base rate analysis to obtain pared-down (quantified) likelihood estimates of the offender being a stranger by seeing what percentage of homicide cases involving a knife and strangle wire also involved a stranger offender (this number, the pared-down base rate, would constitute the likelihood estimate).

1) Narratively combine the above to obtain 1) an argument, and 2) a quantification.

1) Obtain the prior likelihood of the offender being a stranger to the victim (this could be the simple base percentage of stranger homicides among all homicides, or an investigator's initial opinion).

2) Produce a conditional likelihood, based on the database, of an offender using a knife and wire given the offender is a stranger to the victim.

1) Combine the prior, likelihood, and the case data using Bayes' theorem. In this way, the probability that the offender is a stranger to the victim, based on the fact that the offender used a knife and wire, can be explicitly assessed within the context of the (specific) pertinent data, and a singular value can be obtained. 
that a Bayesian approach can improve estimation of guilt, and suggest assigning probability ranges to single or multiple pieces of evidence. They note that this does not solve the problem of assigning "guilt" values to pieces of evidence, but the approach can result in "more systematic assessments and improved investigative decision making" (Blair and Rossmo 2010 p. 133). On a cautionary note, when using databases of convicted criminals to estimate guilt, both the Bayesian and frequentist statistical approaches may perpetuate biases in a system of justice. That is, using the "usual suspects" to predict characteristics of offenders could lead to further focus on these individuals at the expense of other potential investigative leads. The Bayesian approach is not immune to this criticism, though it is less vulnerable to the specific claim that its inherent logic is biased to this conclusion. Frequentist approaches assume the validity of a null hypothesis, that is, they assume the predictor and outcome variables may legitimately be thought to not be related. When this logic is used to evaluate a candidate suspect whose prior offenses are used in the model quantifying his guilt, this assumption is grossly violated and the logic of the frequentist estimator is circular. That is, the offender's statistical relationship to himself is used as o dence against him because the test, in assuming $\mathrm{n}$-relationship, finds his relationship to himself "signif an'". In frequentist approaches, this is a violation of the "ic of the method. In Bayesian approaches this ; not a lo c al violation (since no null assumption is equ. and the context of the information is adequacty incor orated). However, the potential for an offe der's resemblance to himself to make his candidacy as a s nect more likely still remains. The potential for this concer.... ould be considered when using any statistical ind to parse local databases for BIA consultancy.

Table 2 presents a pro edura comparison of two approaches to investig ang taken from Salo et al. (2012) and Alle ret al. press). These papers empirically compare $\mathrm{Ba}$, ian to hon-Bayesian prediction for investigative advising lo et al. (2012) informs column a. The stu dy comparea use of a Bayesian updating model with a ensio al model to link homicide cases using on ffenc behavioural information (i.e., only details $f_{\text {wh }}$ t the offender did). Both models utilized identical re worla data. The Bayesian approach, by better accoun. $\mathrm{g}$ for absent information, resulted in $83.6 \%$ of cases being correctly classified, versus $62.9 \%$ by the dimensional approach. Allen et al. (in press) informs column b. The study compared an empirical Bayesian approach to a "pared-down" base rate method of estimating offender characteristics. The Bayesian approach, by incorporating more contextual information, resulted in $74.6 \%$ prediction accuracy versus $63.5 \%$ accuracy of the base rate method.
Bayesian methods are subject to a disproportionate amount of criticism for being "subjective" and prone to misuse (e.g., Doren 2006). This is due in part to the forthright philosophy of Bayesian analysis, which formally "confesses" that Bayesian estimates like all other estimates, are a product of, and represenc. of, I eliefs about the hypothesis being explored. Popper. ofjectivity requires that the statements an evidence be entirely in observable space (Popper 1972). orefore, provided all the values used in an a ralysis are noroughly explained and justified, Bayesi methols are no less objective than their freque ist ter parts (which involve many subjective choir os).

Bayesian method an form $y$ contextualize, and thus improve, frequen ist lysis. In the 20th century, insurance compan used Bc ésian inverse probability, contrary to a abid Fisherian zeitgeist, without knowing that their co 'utauons were incorporating Bayes' theorem (McGrayn 2011). Similarly, courts in the United States heen using Bayesian risk assessments (Donald on and Wollert 2008; Wollert 2007) while also lambastin „B Bayesian approaches (e.g., Doren 2006). Conrsely, BIA research has largely used frequentist $m$ hods to perform a fundamentally Bayesian task. Whatever the reputation of Bayesian analysis, the task and field of BIA are fundamentally Bayesian. A Bayesian approach to investigative advising is therefore the most logical and promising way forward.

Abbreviation

BIA: Behavioural investigative advising.

\section{Competing interests}

The author declares he has no competing interests.

\section{Acknowledgements}

Thank you to all five reviewers and the editorial staff, with special credit to Reviewer 4 for improving the manuscript's technical rigor. This research was funded in part by the Social Sciences and Humanities Research Council of Canada.

Received: 2 August 2013 Accepted: 11 November 2013 Published: 7 April 2014

\section{References}

Alison L, Rainbow L (ed) (2011) Professionalizing offender profiling: forensic and investigative psychology in practice. Routledge, London

Alison L, Smith MD, Eastman O, Rainbow L (2003) Toulmins philosophy of argument and its relevance to offender profiling. Psychol Crime Law 9(2):173-183

Allen JC, Goodwill AM, Watters K, Beauregard E (in press) Base rates and Bayes' theorem for decision support. Policing: An Int J Police Strateg Manage

Almond L, Alison L, Porter L (2011) An evaluation and comparison of claims made in behavioural investigative advice reports compiled by the National Policing Improvement Agency in the United Kingdom. In: Alison L, Rainbow $L$ (ed) Professionalizing offender profiling: forensic and investigative psychology in practice. Routledge, London, pp 250-263

Blair JP, Rossmo DK (2010) Evidence in context: Bayes' theorem and investigations. Police Q 13:123-135

De Morgan A (1838) An essay on probabilities and their application to life contingencies and insurance offices. Longman, Orme, Brown, Green, \& Longmans, London 
Donaldson T, Wollert R (2008) A mathematical proof and example that Bayes's theorem is fundamental to actuarial estimates of sexual recidivism risk. Sex Abuse 20(2):206-217

Doren DM (2006) Battling with Bayes: when statistical analyses just won't do. Sex Offender Law Report 7(4):49-50. 60-61

Dowden C, Bennell C, Bloomfield S (2007) Advances in offender profiling: a systematic review of the profiling literature published over the past three decades. Journal of Police and Criminal Psychology 22:44-56

Gill J (2009) Bayesian methods, a social and behavioural sciences approach, 2nd edition. CRC Press, London

McGrayne SB (2011) The theory that would not die: how Bayes' rule cracked the enigma code, hunted down Russian submarines, and emerged triumphant from two centuries of controversy. Yale University Press, New York

Popper K (1972) Objective knowledge: an evolutionary approach. Oxford University Press, London

Rainbow $L$ (2011) The UK approach to the management of behavioural investigative advice. In: Alison L, Rainbow L (ed) Professionalizing offender profiling: forensic and investigative psychology in practice. Routledge, London, pp 5-17

Rainbow L, Almond L, Alison L (2011) BIA support to investigative decision making. In: Alison $L$, Rainbow $L$ (ed) Professionalizing offender profiling: forensic and investigative psychology in practice. Routledge, London, pp 35-50

Rossmo DK (2000) Geographic profiling. CRC Press, New York

Rossmo DK (2009) Geographic profiling in serial rape investigations. In: Hazelwood RR, Burgess AW (ed) Practical aspects of rape investigation: a multidisciplinary approach, 4th edition. CRC Press, Boca Raton, pp 139-170

Salo B, Sirén J, Corander J, Zappalà A, Bosco D, Mokros A, Santtila P (2012) Using Bayes' theorem in behavioural crime linking of serial homicide. Leg Criminol Psychol. Advance online publication. doi:10.1111/j.2044-8333.2011.02043.x

Schneps L, Colmez C (2013) Math on trial: how numbers get used and abuse the courtroom. Basic Books, New York

Tartoni F, Aitken C, Garbolino P, Biedermann A (2006) Bayesian network and probabilistic inference in forensic science. John Wiley \& Sons, Ltd NeW York

Wells GL, Turtle JW (1986) Eyewitness identification: the importance models. Psychol Bull 99(3):320-329

Wollert R (2007) Poor diagnostic reliability, the null-Bayes loo nodel, and implications for sexually violent predator evaluations sych vy, Public Policy, and Law 13(3):167-203

Woodhams J, Bull R, Hollin C (2007) Case linkage-id ntifying crimes c, mmitted by the same offender. In Kocsis (Ed.), Criminal rofiling: International theory, research, and practice (pp. 117-133). Humana sss Inc., To owa, NJ

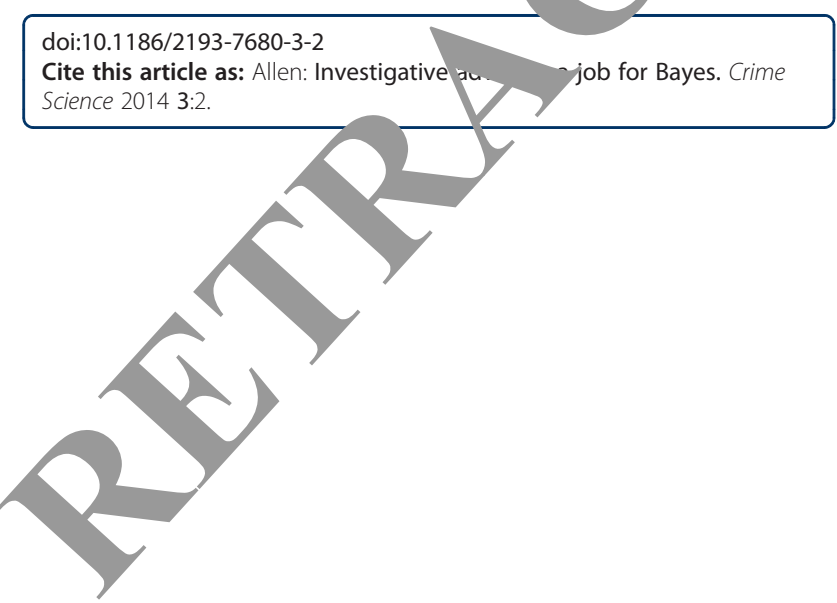

\section{Submit your manuscript to a SpringerOpen ${ }^{\circ}$ journal and benefit from:}

- Convenient online submission

- Rigorous peer review

- Immediate publication on acceptance

- Open access: articles freely available online

- High visibility within the field

- Retaining the copyright to your article

Submit your next manuscript at $\gg$ springeropen.com 